\title{
REFERENCES
}

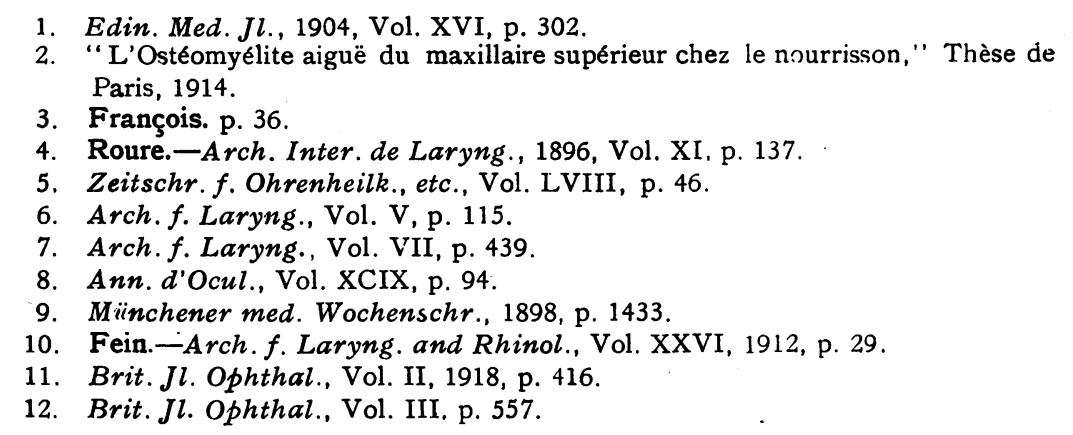

\section{MEGALOPHTHALMUS AND MICROPHTHALMUS}

BY

R. E. Wright, M.D., Major, I.M.S.

MADRAS

IN the Transactions of the Ophthalmological Society of the United Kingdom, 1920, Vol. XL, p. 132 et seq., will be found an interesting communication by $\mathrm{Mr}$. Treacher Collins on megalocornea and microcornea, in which the conditions known as megalocornea, megalophthalmus, hydrophthalmus congenitus, microcornea, nanophthalmia, and microphthalmus are referred to.

As some of these conditions are of great interest and rarity, and as I am not certain as to what class of case Seefelder (quoted by Mr. Collins), includes under the term megalophthalmus, I feel that it is not out of place to publish the following notes.

Buphthalmus (infantile glaucoma, hydrophthalmus congenitus) is comparatively frequent in South India, and although I have come across cases with comparatively good vision and normal tension, with practically symmetrical eyes, I have never seen a case in which there was not considerable deep corneal opacity, very obvious on examination with loupe or microscope. In the beginning of this year a case was met with which did not give the impression of hydrophthalmus congenitus, nor yet did it comply with the conditions which, as stated by Seefelder, distinguish Megalocornea. The case may perhaps be referred to as one of megalophthalmus.

Brief notes are as follows:-

D. S., Mahomedan, aged 45, admitted 22/3/21 for cataract B.E. 
Dimness of vision started five years before, and became very bad inside last few years. The L.E. was interfered with by a coucher three years ago.

R.E.V.=H.M. L.E.V.=P.L. T.=N., B.E. (McLean).

R.E. Pterygium nasal side', a few punctate corneal opacitiès near its head. Cornea very large, uniformly curved, measures 14 $\mathrm{mm}$. vertically, $15 \mathrm{~mm}$. horizontally. Eyeball measures approximately $27 \mathrm{~mm}$. both ways. Pupil round and active, iris tremulous, healthy, of a uniform brown colour. A.C. very deep. Morgagnian cataract, some points of calcareous deposit on the nucleus, spotted capsule, fluid almost absorbed. With corneal microscope the opacities are seen to be in the middle of the substantia propria, the deep layers of the cornea are clear. The opaque fibrous overlap of the sclera appears abnormally drawn out, approximately $2.5 \mathrm{~mm}$. above, somewhat less below.

L.E. As above, except no pterygium; cornea perfectly clear. The lens tremulous and subluxated backwards (suspensory torn below). Capsule considerably more spotted, and more extensive calcareous deposits in the nucleus.

B.E. The globes are symmetrical in size, the curvatures of sclerae and corneae similar.

The man was a fine muscular healthy specimen, intelligent, had learned to read at school, never had any trouble with his eyes, read print at average distance up to the time of developing cataract. There was no thyroid enlargement. Venereal history and signs of disease wanting, Wasserman negative. Urine free from albumen and sugar. Nothing of interest in connection with family history. Curvature of corneae not estimated with keratometer.

29/3/21. Extraction of cataract. R.E. (Madras method.)

The cornea appeared to be thicker on section than average. The nucleus was large (unfortunately not weighed or measured). Post operative course uneventful.

On $5 / 4 / 21$ R.E.V. with plus $10=5 / 30$, with plus $14=\mathrm{J}$. 3 . ᄋ Fundus examination showed fine dust like vitreous opacities. No cupping of the disc, fundus seen best with plus 12 . Ordered subconjunctival cyanide of mercury injections.

21/4/21. The L.E. was operated on. Prior to making the $N$ section, a very fine hollow needle was introduced into the A.C. ్ㅔ which was emptied, $0.6 \mathrm{cc}$. fluid being drawn off. This gives an idea of the size of the A.C. One rarely gets more than $0.3 \mathrm{cc} .0$ in an average eye when carrying out this procedure for cultural purposes. The aqueous was slightly albuminous. The chamber was allowed to refill and section made in the ordinary way. Owing to the subluxation the large nucleus had to be wheeled out with the needle. Some thin vitreous adhered to it, but there was 
no escape. Post operative progress uneventful. On 29/4/21 the chamber was formed, section smooth, eye quiet.

The fundus showed a large splash of white (old haemorrhage) to nasal side of disc. There was no cupping. Fine vitreous opacities were present.

On $5 / 5 / 21$ he was discharged.

R.E.V. with a plus $10=5 / 20$. L.E.V. with a plus $10=5 / 30$. Of six cases of microphthalmus seen in the past year (of which I retained notes), only one could possibly come under the heading microcornea as defined by Mr. Collins. In this case, although the corneae were small $(9 \mathrm{~mm}$. vertical diameter), the iris normal on either side, the scleral portions of the globe apparently normal in size, and the eyes symmetrical, one could not exclude all congenital abnormalities as there was cataract. The other five cases all showed either colobomata or irregularities in the size or shape of the globe as a whole, and asymmetry.

\section{ANNOTATIONS}

\section{The Teaching and Examination of Medical Students in Ophthalmology}

The Report of the Examination Committee of the General Medical Council, considered on November 26, contained the following clause (Lancet, December 10, p. 1,238) :-

"Diseases of the Eye, Ear, and Throat. The inspectors in Medicine and Surgery recommended that Candidates' knowledge of these diseases should either be efficiently tested in the final examination, or should produce evidence that they had been sufficiently instructed and tested as to their knowledge of these subjects."

It will be remembered that the Council of British Ophthalmologists issued a report on the Teaching and Examination of Medical Students in Ophthalmology in 1919 (this Journal, April, 1919). Annotations on this subject appeared in the Journal in the June, July, August, and October numbers of that year, and in the July number of 1920 . The recommendations of the Council of British Ophthalmologists were as follows :-

1.) No student shall be admitted to the final examination, qualifying to practise medicine, unless he has attended an ophthalmic clinic for not less than six hours a week during a period 